\title{
Fabrication and Machining Performance of Powder Compacted Alumina Based Cutting Tool
}

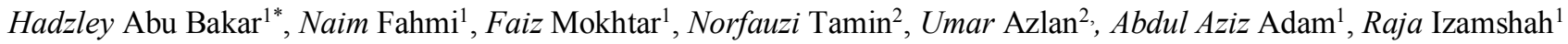 \\ and Shahir Kasim ${ }^{1}$ \\ ${ }^{1}$ Faculty of Manufacturing Engineering, Universiti Teknikal Malaysia Melaka (UTeM), Hang Tuah Jaya, 76100 Durian Tunggal, \\ Melaka, Malaysia \\ ${ }^{2}$ Faculty of Engineering Technology, Universiti Teknikal Malaysia Melaka (UTeM), Hang Tuah Jaya, 76100 Durian Tunggal, Melaka, \\ Malaysia
}

\begin{abstract}
This study focuses on the fabrication of alumina based cutting tool for machining application. Specific weight of alumina powders were pressed in a mold using hydraulic press at 8 tons before compressed through Cold Isostatic Press (CIP) at 30000 psi. Green body then was dried and sintered at $1700{ }^{\circ} \mathrm{C}$ at 4 hours sintering time to form solid cutting tools. These cutting tools were then tested in turning operation to machine AISI 1045 with different cutting speeds. The results shows that CIP pressed alumina cutting tool obtained the hardness of 83.2 HRA which is considered adequate to machine AISI 1045 steel. The shrinkage of alumina powders recorded about $7 \%$ form green compact to sintered body. In terms of flank wear, the alumina cutting tool demonstrated decreased wear rate as the cutting speed increased from $150 \mathrm{~m} / \mathrm{min}$ to $225 \mathrm{~m} / \mathrm{min}$. Wear area focused at the edge of cutting tool due to small nose radius with the minimum wear rate recorded at $0.0025 \mathrm{~mm} / \mathrm{s}$ for $225 \mathrm{~m} / \mathrm{min}$ cutting speed. The newly fabricated cutting tools can be improved if finer or secondary reinforced particles were used.
\end{abstract}

\subsection{Introduction}

Ceramic cutting tool is a material produced by the combination of ceramic powders that are compacted and applied at machining operations. There are many example of ceramic cutting tool such as silicon nitride, silicon carbide, sialon and titanium carbide [1]. Ceramic cutting tools have been widely used in machining hard material due to its excellent properties especially in high temperature and high speed machining. This cutting tool tool can be fabricated by the powder metallurgy processes. Specific composition of ceramic powders can be compacted with mixture and milling with other reinforced materials to create refractory body for high performance in tribology applications [2].

There are many technique to process ceramic powders such as slip casting, ball milling and slurry mixing. Another secondary processes that involve are pressing, sintering grinding or polishing. The efficiency of ceramic cutting tools depended on many factors. Among dominant one are characteristics of powders that used as raw materials, additive materials, sintering temperature and the geometry of cutting tools. In order to evaluate the performance of ceramic cutting tool, several criteria can be employed such as hardness, density, wear performance and surface roughness of the machined surface [3].

Wear performance of ceramic compact is very important in order to run prolong machining operation. The major causes of tool wear are mechanical, thermal, chemical and abrasion [4]. Most of the cutting processes in machining are done by the nose radius of the inserts. The stability of nose radius during contact action with the workpiece material rely on the structure and bonding strength between composition of particles that integrated within cutting tools. Strong bonding between particles would lead to higher tribological wear resistance. In addition, the integrated particles should also have high hot hardness to retain its stability at elevated temperature [5].

Among many ceramic cutting tools that available in industry, alumina based materials are among the most popular choices to be used as cutting tools. Alumina based cutting tool reportedly has high resistance to heat, abrasion and chemical inertness against the enviroment and the workpiece [6]. In the application of alumina as a cutting tool, important criteria such as microstucture, grain size, grain uniform and reinforced particle are very important. Fine and uniform grain size would provide high resistance to wear when this powder compact engages with other materials [7].

Due to recent development and advancement in ceramic technology, some better quality of alumina powders have been discovered and reportedly have excellent performance in machining [8]. Such ceramic powders are prepared from various type of processes in order to enhance the properties so that the powders can be manufactured into excellent products. Therefore, it is a very good oppurtunity to fabricate a cutting tools from these ceramic powders and study their potential in

\footnotetext{
* Corresponding author: hadzley@utem.edu.my
} 
machining. This paper presents the fabrication of ceramic cutting tool based on the specific composition of alumina powder. As the ceramic powders were compacted and sintered, the performance of ceramic cutting tool was evaluated based on wear performance and surface roughness of the machined surface. Selected cutting tools were used to machine AISI 1045 by the CNC machine at various cutting parameters. The evaluation of this research was examined using stereo microscope. This project also presented the failure mode of the newly fabricated cutting tool to highlight the possible weaknesses from the manufacturing processes. In the end, this result will be used to propose some improvement or refinement for the cutting tool development in the future.

\subsection{Methodology}

\subsection{Fabrication of ceramic insert}

Specific amount of $4 \mathrm{~g}$ alumina was prepared and shaping process was done in a mould by pressing using hydraulic hand press with pressure of 8 tons. The pressure was increased by 2 tonns and rested for 1 minutes during the compaction process. After the pressure reached 8 tonns, the green body was ready to be ejected from the mould. Then, the green body was pressed using cold isostatic press (CIP) with 30000 psi pressure. After the process completed, the compacted green body was taken out from the chamber. Series of sintering were implemented at $1700{ }^{\circ} \mathrm{C}$ with 4 hours soaking time. Figure 1 shows the sequence of cutting tool manufacturing produced in this study. Shrinkage of compacted alumina were measure based on length and thickness and hardness were evaluated using Rockwell hardness tester.
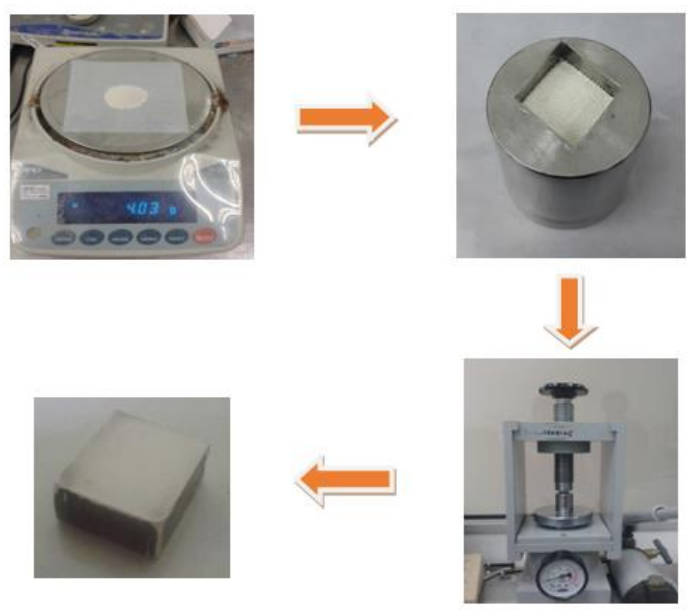

Fig. 1. Pre-compaction process of alumina powder into compacted green body

\subsection{Machining tests}

The second stage of this experiment was the machining performance test on the newly fabricated alumina cutting tools. The machining test was performed using CNC lathe machine as shown in Figure 2. The workpiece materials selected was AISI 1045 medium carbon steel with straight turning process as shown in Figure 3 (a-d). The dimension of the workpiece was $150 \mathrm{~mm}$ length and $50 \mathrm{~mm}$ diameter.

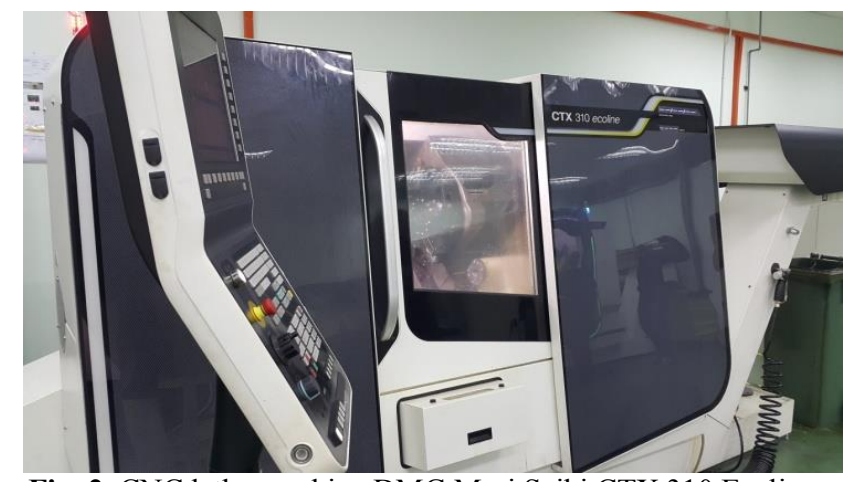

Fig. 2. CNC lathe machine DMG Mori Seiki CTX 310 Ecoline

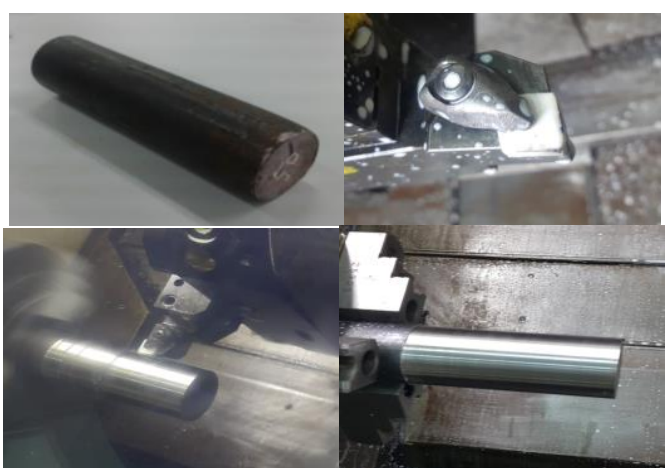

Fig. 3. (a) Workpiece material of AISI 1045 (b)Alumina cutting tool on tool holder (b) Straight turning operation (c) machined surface of AISI 1045

The machining trials was designed by varying the cutting speeds as shown in Table 1. Only one straight layer of workpiece was machined within the cutting length around $150 \mathrm{~mm}$. Tool wear on cutting tool was measured using a stereo microscope based on average values. The wear rate of the cutting tool was calculated by dividing the average flank wear on both sides with the cutting time.

Table 1. Machining parameters

\begin{tabular}{|c|c|c|c|}
\hline $\begin{array}{c}\text { Cutting } \\
\text { Tool }\end{array}$ & $\begin{array}{c}\text { Cutting } \\
\text { Speed } \\
(\mathbf{m} / \mathbf{m i n})\end{array}$ & $\begin{array}{c}\text { Feed Rate } \\
(\mathbf{m m} / \mathbf{r e v})\end{array}$ & $\begin{array}{c}\text { Depth of } \\
\text { Cut }(\mathbf{m m})\end{array}$ \\
\hline Tool 1 & 150 & 0.05 & 1 \\
\hline Tool 2 & 175 & 0.05 & 1 \\
\hline Tool 3 & 200 & 0.05 & 1 \\
\hline Tool 4 & 225 & 0.05 & 1 \\
\hline
\end{tabular}

\subsection{Results and Discussion}

\subsection{Properties of fabricated cutting tool}

Figure 4(a) shows the image of the compacted green body after being pressed with hydraulic hand press and cold isostatic press at 30000 psi, before sintering process. The sample appeared in brownish white with 
scar marks at the side of cutting tool. The size of this green compact was around maximum $13.00 \mathrm{~mm}$ length and $5.9 \mathrm{~mm}$ thickness. Figure 4(b) shows the fabricated alumina cutting tool after sintering. The colour of alumina compact changed to milky white. The size of sintered cutting tool was reduced up to $12.7 \mathrm{~mm}$ length and $5.3 \mathrm{~mm}$ thickness. Overall, the total shrinkage of alumina compact before and after sintering recorded maximum $7.01 \%$. Table 2 shows the details of shrinkage dimension for all samples measured.

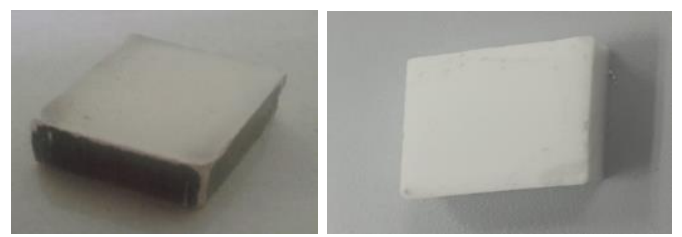

Fig. 4. (a) Compacted green body before sintering (b) Alumina cutting tool after sintering

Table 2. Percentage of shrinkage of the alumina cutting tool after sintering

\begin{tabular}{|l|c|c|c|c|l|}
\hline \multirow{2}{*}{$\begin{array}{l}\text { Cutting } \\
\text { Tool }\end{array}$} & \multicolumn{2}{|c|}{ Before Sintering } & \multicolumn{2}{|c|}{ After Sintering } & Shrin \\
\cline { 2 - 5 } & $\begin{array}{c}\text { Length } \\
(\mathrm{mm})\end{array}$ & $\begin{array}{c}\text { Thick } \\
\text { ness } \\
(\mathrm{mm})\end{array}$ & $\begin{array}{c}\text { Length } \\
(\mathrm{mm})\end{array}$ & $\begin{array}{l}\text { Thick } \\
\text { ness } \\
(\mathrm{mm})\end{array}$ & $\begin{array}{l}\text { kage } \\
(\%)\end{array}$ \\
\hline Tool 1 & 12.9 & 5.9 & 12.8 & 5.5 & 6.78 \\
\hline Tool 2 & 12.8 & 5.7 & 12.7 & 5.3 & 7.01 \\
\hline Tool 3 & 13.0 & 5.9 & 12.9 & 5.4 & 8.47 \\
\hline Tool 4 & 12.9 & 5.8 & 12.8 & 5.3 & 8.62 \\
\hline
\end{tabular}

During sintering, the high temperature that absorbed by the ceramic compacts resulting isolated grain growth of the alumina particles. This resulting nucleation between particles, which in the end reduced the porosity between particles compact. As the grain particles bind closely to each other, the diffusion among particles resembles a close packed mass of powder particles. As a result, the structure of the alumina cutting tool became denser, translated into shrinkage of solid material [9].

The densification of alumina compact after sintering enable these inserts to increse their hardness and mechanical properties. As shown in Table 3, maximum hardness of 85.3 HRA was recorded and this value considered 4 times higher as compared to AISI 1045. Such adequate hardness benefitted the cutting tool to shear the steel effectively ecspecially when the dense structure finely integrated at the tool nose radius. This highlighted their potential to be a promising cutting tool, even with simple manufacturing procedure.

Table 3. Hardness value of alumina cutting tools

\begin{tabular}{|c|c|c|c|c|}
\hline \multirow{2}{*}{$\begin{array}{c}\text { Cutting } \\
\text { Tool }\end{array}$} & \multicolumn{4}{|c|}{ Hardness Value (HRA) } \\
\cline { 2 - 5 } & 1 & 2 & 3 & Average \\
\hline Tool 1 & 83.4 & 85.1 & 75.9 & 81.5 \\
\hline Tool 2 & 83.8 & 84.6 & 82.7 & 83.7 \\
\hline Tool 3 & 85.3 & 84.7 & 82.1 & 84.0 \\
\hline Tool 4 & 82.8 & 84.3 & 83.0 & 83.4 \\
\hline \multicolumn{4}{|c|}{ Average hardness of all tools } & 83.2 \\
\hline
\end{tabular}

\subsection{Wear performance of fabricated cutting tool}

After the fabrication process, the fabricated cutting tools were tested by turning process at various cutting speeds. The performance of the cutting tools were analyzed based on wear performance and failure modes. Table 4 shows the average wear and wear rate measured at a cutting distance around $150 \mathrm{~mm}$ cutting length. Figure 5 shows the trend in flank wear rate of the alumina cutting tool when machining AISI 1045 with different cutting speeds at constant $0.05 \mathrm{~mm} / \mathrm{rev}$ feed rate and $1 \mathrm{~mm}$ depth of cut. Based on the graph, the wear rate dropped slightly from cutting speed $150 \mathrm{~m} / \mathrm{min}$ to $175 \mathrm{~m} / \mathrm{min}$. However, the wear rate decreased drastically from cutting speed $175 \mathrm{~m} / \mathrm{min}$ to $200 \mathrm{~m} / \mathrm{min}$. The wear rate mantained similar value on the last run. From this graph, it shows that the highest flank wear rate occurred at cutting speed $150 \mathrm{~m} / \mathrm{min}$ with the value of $0.0041 \mathrm{~mm} / \mathrm{s}$. The lowest flank wear rate recorded at $0.0025 \mathrm{~mm} / \mathrm{s}$ which occurred at cutting speeds of $200 \mathrm{~m} / \mathrm{min}$ and 225 $\mathrm{m} / \mathrm{min}$.

Table 4. Wear rates of each cutting tool at different cutting speeds.

\begin{tabular}{|c|c|c|c|}
\hline Tool & $\begin{array}{c}\text { Cutting Speed } \\
(\mathrm{m} / \mathrm{min})\end{array}$ & $\begin{array}{c}\text { Average Wear } \\
(\mathrm{mm})\end{array}$ & $\begin{array}{c}\text { Wear Rate } \\
(\mathrm{mm} / \mathrm{s})\end{array}$ \\
\hline 1 & 150 & 0.62 & 0.0041 \\
\hline 2 & 175 & 0.43 & 0.0040 \\
\hline 3 & 200 & 0.18 & 0.0025 \\
\hline 4 & 225 & 0.15 & 0.0025 \\
\hline
\end{tabular}

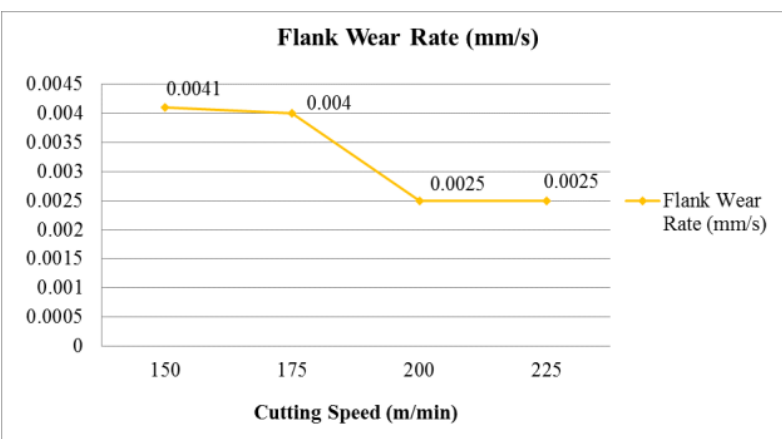

Fig. 5. Flank wear rate of alumina cutting tools at different cutting speeds

\subsection{Failure modes of fabricated cutting tool}

Figure 6 shows the failure modes of cutting tools tested. It shows that the wear of the fabricated cutting tools concetrated at the edge of cutting tool, notched far to the flank face. Obviously, wear occured at the flank face, combined with the abrasive and notch wears. Small nose radius could be the major reason of poor wear performance. Flank wear happen when the relief face of a cutting tool and the workpiece rub each other, resulting material loss due to abrasion mechanisms. During contact shearing between cutting tool and workpiece, high friction occurred at the tool-workpiece interfaces caused the temperature generated. At that particular point, high temperature at concentrated region 
weakening the edge of tool nose radius. Particles of the cutting tool gradually slide away until certain limit where the cutting tool could not retain its structural integrity, facilitating major damaged to the shape of nose radius. As shape of nose radius damaged, cutting force would not be uniform anymore and caused more friction to occur. Thus, machining action will be no more efficient. Further cutting action will destroy the edge of cutting tool [10].

Another observation of failure modes that occurred at the cutting edge is crater wear. This is shows in Figure 7 where the crater region apparently appeared on the rake face of the cutting tool. Crater wear occurred due to heavy sliding from the back side of chip that gradually abrade the contact surfaces of cutting tool. With fast chip movement and high temperature, some portion of particles on the rake face were ploughed as a result of disintegrate structure of cutting edge. There are evidence of flaking on the rake face probably due to higher pressure to the tool edge. At some extent, the flaking phenomena would expose the intermediate structure of cutting tool to the sliding chip. With high cutting temperature, some portion of chip could diffuse into the rake face resulting diffusion wear to occur. Diffusion wear would enhanced structure disintegration at the tool edge resulting heavy damage to the cutting tool [11].
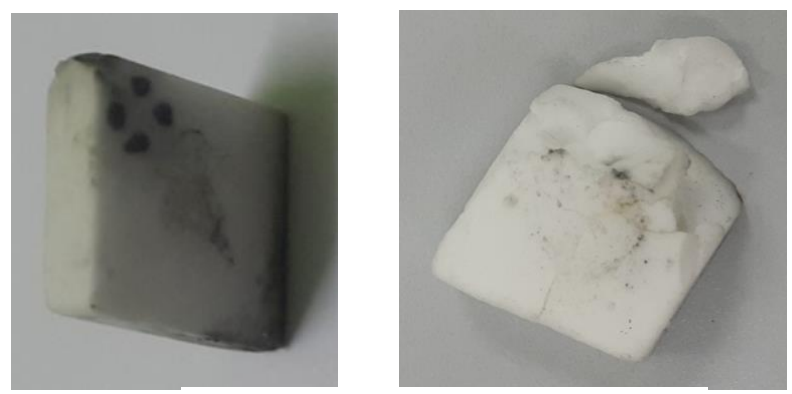

Fig. 6. Failure of fabricated alumina cutting tools

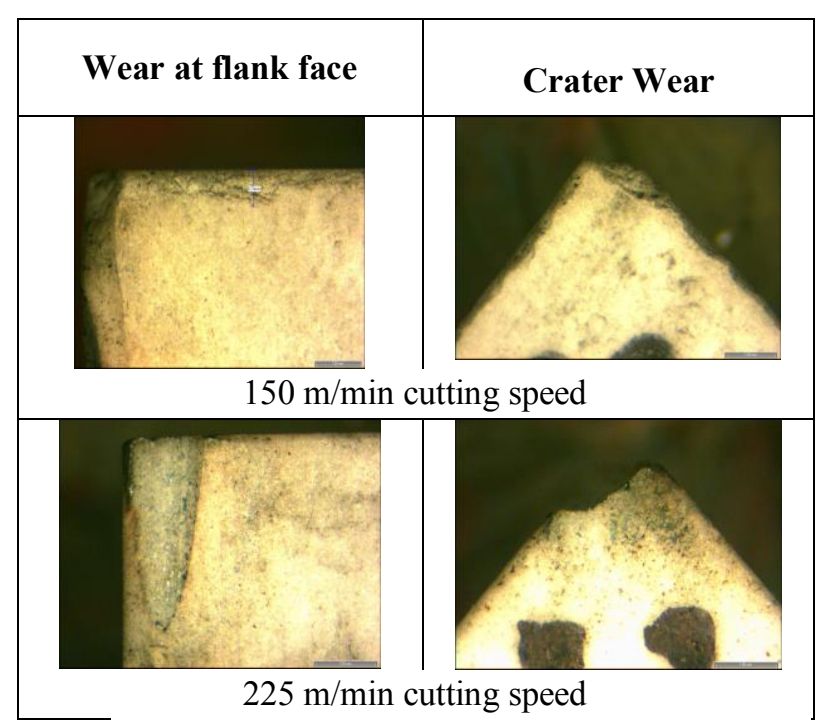

Fig. 7. Flank and cater wears for the fabricated alumina cutting tool at lowest and highest cutting speeds

These findings are differ from the research done by Rejab et. al, 2011 [12] where the flank wear of the alumina cutting tools increased when the cutting speed used is increased. There are several possible factors that can influence the results of this experiment. The first one is, there are some inconsistency in the shape and structure of all four cutting tools that were used for the machining test. The alumina cutting tools were not having perfect shapes for the machining. There were tiny chippings on the structure of the cutting tools which could lead to bigger wear during machining. Therefore, the results of the wear rate were inconsistent among all four cutting tools.

Another possible factor that could lead to this issue is the difference between the grain sizes of the alumina cutting tools. Milak et al. (2015) [13] stated that the flank wear decreases with the reductions in alumina grain sizes. This proves that when a cutting tool has smaller grain sizes as compared to the others, the wear of the tool will be smaller. The grain sizes of tool 1 used at $150 \mathrm{~m} / \mathrm{min}$ might be larger or not consistent than the tool used at $225 \mathrm{~m} / \mathrm{min}$, hence caused higher wear rate.

Other than that, it is expected that the temperature generated during machining AISI 1045 at $150 \mathrm{~m} / \mathrm{min}$ is lower as compared to the cutting speed $225 \mathrm{~m} / \mathrm{min}$. Such low temperature probably not sufficient to soften the steel during machining process and therefore provided difficult for the cutting tool to shear the workpiece material [14]. Due to this problem, the cutting tool was subjected to a higher cutting force which led to higher wear on the cutting edge. On the other hand, when cutting speed of $225 \mathrm{~m} / \mathrm{min}$ applied, higher temperature is expected to be generated during the machining in this facilitate easy cutting process due to softening condition of the workpiece.

Overall, fabrication of alumina-based cutting tools is still in its infancy and has yet to be done extensively. It should be proposed that, even though the wear performance of this newly fabricated cutting tool still far behind to compete the commercial cutting tools, some promising aspects can be demonstrated. The alumina powders selected in this study still capable to be compacted without fracture, even with simple manufacturing procedure. There are still many flaws occurred during the fabrication process that need some improvements so that these newly fabricated cutting tools can match the performance of the other commercialized cutting tools. Therefore for the next experiment, there are some aspects that can be done to improve the properties of the cutting tools. The first approach should be replacing the alumina powder used now with a more refined alumina powder. This is because particle size of the alumina powder used are not refined enough to produce a compact structure. Usage of finer powder will fix some of the weaknesses in terms of density, agglomerates and reduction of porosity. Addition of several additive powders such as zirconia, chromia or silicon carbide could also improve the mechanical properties of the cutting tool.

\subsection{Conclusion}

This study involved fabrication of alumina cutting tool and evaluation of the performance of the cutting tool by 
machining test on AISI 1045 medium carbon steel. Based on the experimental finding the following conclusions can be drawn:

1) The alumina powder used in this study able to be compacted in the mold to form the required shape of cutting tool insert.

2) Sintering of alumina compact resulting denser and stronger structure. All cutting tools had shrinkage at average of $7 \%$ from the initial size and achieved an average of 83.2 HRA hardness.

3) The flank wear rate decreases as the cutting speed increases. The lowest wear rate produced at 0.0025 $\mathrm{mm} / \mathrm{s}$ when cutting speed $225 \mathrm{~m} / \mathrm{min}$ was used.

4) Failure modes of fabricated cutting tool appeared to be flank and crater wears. Small edge of tool nose radius suspected the be main concern for the tool failure.

The authors would like to thank Faculty of Manufacturing Engineering, Faculty of Engineering Technology and Universiti Teknikal Malaysia Melaka (UTeM) for their support that enabled this work to be carried out through the grant of FRGS/1/2017/TK03/UTEM/02/11.

\section{References}

1. S. Kalpakjian, S.R. Schmid. 4th ed. New Jersey: Prentice-Hall (2001)

2. M. Cheng, H. Liu, B. Zhao, C. Huang, B. Wang, Cer. Int. 43-16, 13869-13874, (2017)
3. A.B. Hadzley, S. Sarah, R. Izamshah, M. Amran, M. Shahir, M. Amri, N. Fatin, App. Mech. and Mat 465-466, 1049-1053 (2014).

4. Z., Yin, C., Huang, J., Yuan, B., Zou, H., Liu, \& H. Zhu. Cer. Int., 41(5), 7059-7065. (2015)

5. Xiabon X. Cui, F. Jiao, P. Ming, J. Guo, Cer Int 4313, 10109-10122 (2017)

6. A. A. Zahirani, L. C. Choong, H. Mohamed, M.M. Ratnam, Z. A. Ahmad, J. Ally. Comp. 513, 91-96, (2012)

7. A. A. Zahirani, H. Mohamad, M.M. Ratnam, Z.A. Ahmad., J Ally. Comp. 497, 1-2, 316-320 (2010)

8. A. A Sanusi, A.A Aziz, M.A. Amran, M.S. Kasim, M. Zaimi, R. Izamshah, iDECON 2015

9. N.J. Loh, L. Simao, J. Jiusti, A. De Noni Jr, O.r.K Montedo, Cer. Int. 43-11, 8269-8275 (2017)

10. M. R. Fatin, A.B. Hadzley, R. Izamshah, M.A. Amran, Appl. Mech. Mat. 761, 257-261 (2015)

11. M.S. Kasim, C.H. Che Haron, J.A. Ghani, M.A. Sulaiman, M.Z.A. Yazid, Wear 302, 1-2, 1171-1179 (2013)

12. N. A., Rejab, A. Z. A., Azhar, K. S., Kian, M. M., Ratnam Z. A. Materials Science and Engineering: A, 595, 18-24. (2014)

13. P. C. Milak, F. D. Minattom A. De Noni Jr., O. R. K. Montedo, Cerâmica, 61, 88-103 (2015)

14. M.A. Kamely, M.Y. Noordin, A.Y. Bani Hashim, S.H. Yahya, M.M.P. Dan, J. Adv. Man. Tech. 6-1 (2012). 